\title{
Arborização urbana e Educação Ambiental: estudo de caso com o evento "Arboriza Ponta Grossa"
}

\author{
Urban arborization and Environmental Education: case study with the event "Arboriza Ponta \\ Grossa"
}

Arborización urbana y Educación Ambiental: estudio de caso con el evento "Arboriza Ponta

Grossa"

Recebido: 16/07/2021 | Revisado: 23/07/2021 | Aceito: 30/07/2021 | Publicado: 07/08/2021

\author{
Gerson Luiz dos Santos \\ ORCID: https://orcid.org/0000-0003-1960-2610 \\ Universidade Estadual de Ponta Grossa, Brasil \\ E-mail: gersonluizuepg@gmail.com \\ Carlos André Stuepp \\ ORCID: https://orcid.org/0000-0003-4651-9249 \\ Universidade Estadual de Ponta Grossa, Brasil \\ E-mail: castuepp@uepg.br \\ Sandro Xavier de Campos \\ ORCID: https://orcid.org/0000-0002-7585-7573 \\ Universidade Estadual de Ponta Grossa, Brasil \\ E-mail: campo@uepg.br \\ Rosimeri de Oliveira Fragoso \\ ORCID: https://orcid.org/0000-0002-5842-8208 \\ Universidade Estadual de Ponta Grossa, Brasil \\ E-mail: meri_ol@yahoo.com.br
}

\begin{abstract}
Resumo
A ciência tem mostrado a importância das árvores em ambientes urbanos que, por meio de seus serviços ecossistêmicos, fornecem qualidade de vida à população. Deste modo, levando-se em conta o papel da universidade enquanto formadora de recursos humanos e geradora de ciência aplicada à qualidade de vida e do meio ambiente, objetivou-se investigar como o evento de extensão "Arboriza Ponta Grossa", organizado anualmente por professores e alunos da Universidade Estadual de Ponta Grossa e responsável pela produção e doação de mudas de espécies arbóreas, se insere no contexto da Educação Ambiental e na construção de referenciais ambientais acerca da importância das árvores no ambiente urbano. Para tanto, a pesquisa fundamentou-se em uma abordagem qualitativa e como ferramenta de coleta de dados utilizou-se um questionário aplicado às pessoas que participaram do evento. As respostas dos questionários foram analisadas a partir das frequências das respostas observadas, utilizando-se ferramentas do programa Excel para a construção de gráficos. Verificou-se que ações extensionistas como o "Arboriza Ponta Grossa" podem ser consideradas eficientes na promoção da interação entre a universidade e a comunidade, além de atender à objetivos de caráter educacionais e didáticos, sendo um importante subsídio para a formação acadêmica de futuros profissionais comprometidos com a sociedade. O alcance do público e a adesão da população ao evento demonstram o elevado interesse dos participantes em inserir espécies arbóreas nos ambientes urbanos, e permite reforçar a importância de ações como essa para sensibilizar a comunidade sobre o valor ecológico, social e econômico das florestas urbanas.
\end{abstract}

Palavras-chave: Doação de mudas; Extensão universitária; Florestas urbanas.

\begin{abstract}
Science has shown the importance of trees in urban environments that, through their ecosystem services, provide quality of life to the population. Thus, taking into account the role of the university as a trainer of human resources and a generator of science applied to the quality of life and the environment, the present study aimed to investigate how the extension event "Arboriza Ponta Grossa", organized annually by Professors and undergrad students of the State University of Ponta Grossa, responsible for the production and donation of seedlings of tree species and passing on information on the planning of urban afforestation, is inserted in the context of Environmental Education and in the construction of environmental references about the importance of trees in the urban environment. Therefore, the research was based on a qualitative approach and as a data collection tool a questionnaire applied to people who participated in the event was used. The responses to the questionnaires were analyzed based on the frequencies of the responses observed, using tools from the Excel program to build graphs. It was observed that extension events such as "Arboriza Ponta Grossa" can be considered efficient in promoting interaction between the university and the
\end{abstract}


community, in addition to meeting educational and didactic objectives, being an important subsidy for the academic education of future professionals committed to society. The good reach of the public and the population's adherence to the event demonstrate the high interest of the participants in raising the percentage of plants in urban environments, and reinforce the importance of actions like this to sensitize the community about the ecological, social and economic value of urban forests.

Keywords: Seedling donation; University extension; Urban forests.

\section{Resumen}

La ciencia ha demostrado la importancia de los árboles en los entornos urbanos que, a través de sus servicios ecosistémicos, proporcionan más calidad de vida a la población. Así, teniendo en cuenta el papel de la universidad como formadora de recursos humanos y generadora de ciencia aplicada a la calidad de vida y al medio ambiente, el presente estudio tuvo como objetivo indagar cómo el evento de extensión "Arboriza Ponta Grossa", organizado anualmente por profesores y estudiantes de la Universidad Estatal de Ponta Grossa, responsable de la producción y donación de plántulas de especies arbóreas y de transmitir información sobre la planificación de la forestación urbana, se inserta en el contexto de la Educación Ambiental y en la construcción de referencias ambientales sobre la importancia de los árboles en el entorno urbano. Por lo tanto, la investigación se basó en un enfoque cualitativo y como herramienta de recolección de datos se utilizó un cuestionario aplicado a las personas que participaron en el evento. Las respuestas a los cuestionarios se analizaron con base en las frecuencias de las respuestas observadas, utilizando herramientas del programa Excel para construir gráficos. Se observó que eventos de extensión como "Arboriza Ponta Grossa" pueden considerarse eficientes en promover la interacción entre la universidad y la comunidad, además de cumplir con los objetivos educativos y didácticos, siendo un importante subsidio para la formación académica de futuros profesionales comprometidos con la sociedad. El buen alcance de la ciudadanía y la adhesión de la población al proyecto demuestran el alto interés de los participantes en elevar el porcentaje de plantas en entornos urbanos, y permite reforzar la importancia de acciones como esta para sensibilizar a la comunidad sobre el valor ecológico, social y económico de los bosques urbanos.

Palabras clave: Donación de plántulas; Extensión universitaria; Bosques urbanos.

\section{Introdução}

A falta de planejamento adequado para a urbanização das cidades no Brasil resulta no seu crescimento desordenado, com consequências sobre a qualidade de vida das pessoas e distanciamento de uma relação harmoniosa com o ambiente natural (Ugeda Júnior, 2016). Entre as medidas citadas pela Organização Mundial da Saúde para que uma cidade se torne saudável, está a construção de um ambiente físico limpo e seguro, e um ecossistema estável e sustentável (OMS, 1995).

Inúmeras pesquisas têm apontado para a importância das árvores em ambientes urbanos, que por meio de seus serviços ecossistêmicos, proporcionam mais qualidade de vida à população, auxiliando tanto na saúde física como mental das pessoas (Londe et al., 2014; Duarte et al., 2017). As árvores embelezam o ambiente, auxiliam na estabilização do clima, na infiltração da água da chuva e na redução das temperaturas do ar durante o verão, além de fornecer abrigo e alimentos para a fauna (Oliveira \& Rosin, 2013). Apesar disso, verifica-se que no Brasil a arborização urbana ainda é uma prática relativamente recente (Gonçalves et al., 2018) e, por essa razão, carece de maiores esforços para que a população compreenda o valor ecológico, social e econômico das florestas urbanas.

Na busca pela melhoria da qualidade do ambiente urbano, há a necessidade de intervenções para que a sociedade se torne mais consciente e detentora dos conhecimentos necessários à construção de soluções eficazes e minimizadoras da crise ambiental (Silva \& Oliveira, 2020). Nesse sentido, o fornecimento de mudas à população para ocupar ambientes urbanos e rurais pode contribuir para o despertar da consciência ambiental e atender uma importante demanda social (Lima et al., 2018), sobretudo em classes socioeconômicas desfavorecidas. Associado a isso, o repasse de conhecimentos sobre planejamento, implantação e manejo das plantas pode reduzir o que se conhece como "cegueira botânica" (Milach et al., 2016), que se refere à ausência de percepção das plantas no ambiente, levando ao não reconhecimento da sua importância na biosfera e para o cotidiano dos seres humanos (Wandersee \& Schussler, 2001; Vasques et al., 2021).

Ações como essas podem ser desenvolvidas por meio da Educação Ambiental, que tem papel essencial na sensibilização das comunidades, mediando a construção de valores e referenciais ambientais (Alencar \& Barbosa, 2018). Isso porque a Educação Ambiental não se limita a um simples método de escolarização sobre os problemas ambientais do Planeta, 
mas é uma forma de conscientização, sensibilização e transformação dos princípios éticos, sociais e morais dos indivíduos, para que por meio de uma visão holística e crítica, exerçam de forma plena e correta a cidadania (Silva \& Oliveira, 2020). A Educação Ambiental também estimula a sociedade a desenvolver um conhecimento mais complexo, considerando o ambiente em sua totalidade, de modo a facilitar a compreensão do ambiente como um conjunto de relações entre os fatores bióticos e abióticos, conduzindo os indivíduos à percepção de que os problemas ambientais devem ser resolvidos por meio da mudança da relação da sociedade com a natureza (Ferreira et al., 2019).

Assim, considerando a responsabilidade das universidades enquanto formadoras de recursos humanos e geradoras de ciência aplicada à qualidade de vida e do meio ambiente, o Viveiro Florestal da Universidade Estadual de Ponta Grosa (UEPG) e Colégio Agrícola Estadual Augusto Ribas (CAAR), em parceria com a Proplan-Diretoria de gestão ambiental, realizaram o evento de extensão chamado "Arboriza Ponta Grossa". Este evento teve como principal objetivo trazer à ciência da população a importância social, ambiental e econômica das florestas urbanas, além de realizar a produção e doação de espécies arbóreas com aptidão para o ambiente urbano.

Com base neste evento, formulou-se como hipótese desse trabalho que a doação de mudas e conhecimentos sobre as plantas à comunidade tem o potencial de contribuir para o reconhecimento, por parte desta, da importância das árvores para a manutenção dos ecossistemas urbanos e suas funções na melhoria das condições de vida das pessoas. Assim, objetivou-se verificar como o evento de extensão "Arboriza Ponta Grossa" se insere no contexto da Educação Ambiental e na construção de valores e referenciais ambientais acerca da importância das árvores.

\section{Metodologia}

A pesquisa de campo ocorreu no dia 05 de junho de 2020, na Universidade Estadual de Ponta Grossa, durante a segunda edição do evento de extensão "Arboriza Ponta Grossa”, realizado em comemoração ao dia mundial do meio ambiente. O evento foi escolhido para esta pesquisa por ser uma ação tanto de caráter social, como científico e educacional, que desde a sua primeira edição buscou ampliar o conhecimento da população sobre os benefícios das florestas urbanas, bem como atender a dúvidas sobre formas de plantio e manejo, de acordo com a demanda técnica exigida para cada ambiente, oportunizando a interação entre alunos e comunidade.

Para a realização do evento, o Viveiro Florestal UEPG/CAAR produziu mudas de espécies arbóreas nativas com aptidão para a arborização urbana (Tabela 1), sendo as mudas que atingiram qualidade morfológica adequada, preparadas para a doação à comunidade. Devido à pandemia do Covid-19 presente neste ano, a doação foi realizada em modelo drive-thru, no qual o atendimento à comunidade ocorreu junto aos veículos dos participantes, observando-se todas as medidas de distanciamento social e demais medidas de segurança necessárias. 
Tabela 1 - Lista de espécies produzidas pelo Viveiro Florestal UEPG/CAAR para doação no evento de extensão “Arboriza Ponta Grossa" realizado no dia 5 de junho de 2020, no município de Ponta Grossa-PR.

\begin{tabular}{|c|c|}
\hline Nome Popular & Nome Científico \\
\hline Angico-branco & Anadenanthera colubrina (Vell.) Brenan \\
\hline Angico-vermelho & Parapiptadenia rigida (Benth.) Brenan \\
\hline Araçá-vermelho & Psidium cattleyanum Sabine \\
\hline Cerejeira-do-Rio-Grande & Eugenia involucrata DC. \\
\hline Dedaleiro & Lafoensia pacari A.St.-Hil. \\
\hline Espinheira-santa & Monteverdia ilicifolia (Mart. ex Reissek) Biral \\
\hline Ipê-amarelo & Handroanthus chrysotrichus (Mart. ex DC.) Mattos \\
\hline Ipê-rosa & Ceiba speciosa (A.St.-Hil.) Ravenna \\
\hline Jabuticaba & Plinia peruviana (Poir.) Govaerts \\
\hline Manduirana & Senna macranthera (DC. ex Collad.) H.S.Irwin \& Barneby \\
\hline Monjoleiro & Senegalia polyphylla (DC.) Britton \& Rose \\
\hline Pinheiro-do-Paraná & Araucaria angustifolia (Bertol.) Kuntze \\
\hline Pitanga & Eugenia uniflora $\mathrm{L}$. \\
\hline Sibipiruna & Cenostigma pluviosum (DC.) Gagnon \& G.P.Lewis \\
\hline Uvarana & Cordyline spectabilis Kunth \& Bouché \\
\hline
\end{tabular}

Fonte: Autores.

Como o repasse de conhecimento era um fator preponderante para os organizadores do evento, os professores responsáveis realizaram um treinamento prévio com os alunos colaboradores da ação, para que os mesmos pudessem orientar a população a respeito do plantio, cuidados e condução das mudas, além de promoverem a sensibilização dos participantes a respeito da importância da arborização, seja urbana ou rural. Além disso, foi elaborado um folder contendo informações sobre plantio, poda, tutoramento e espécies indicadas para cada local de plantio (Figura 1), o qual foi entregue à cada participante junto com as mudas doadas. 
Figura 1 - Folder informativo fornecido aos participantes do evento de extensão "Arboriza Ponta Grossa" realizado no dia 5 de junho de 2020, no município de Ponta Grossa-PR.
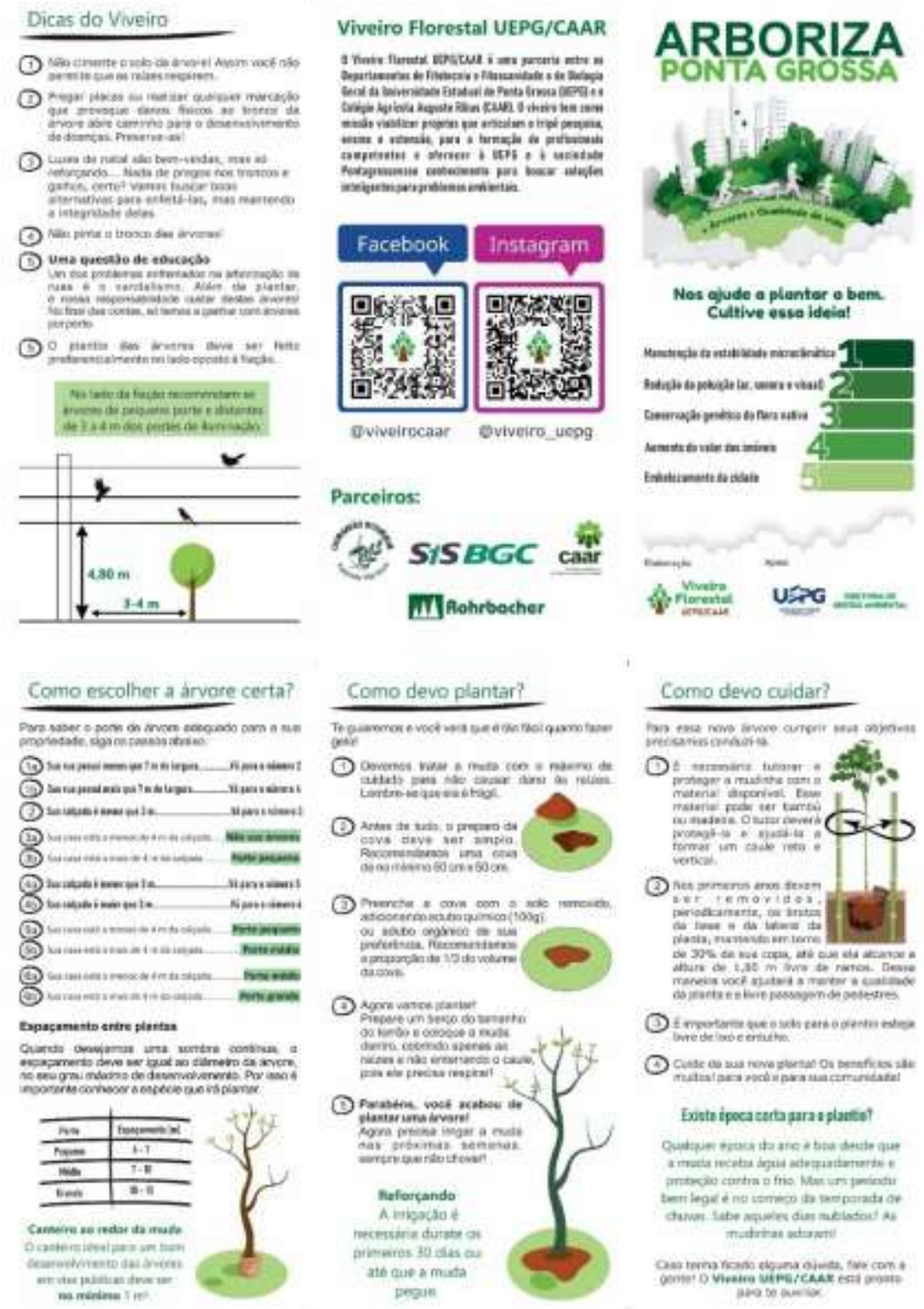

Fonte: Autores.

Previamente ao evento, também foram disponibilizadas informações sobre cada espécie por meio de fichas dendrológicas inseridas nas redes sociais do Viveiro Florestal UEPG/CAAR (Figura 2), com o intuito de facilitar a escolha das mudas pela população no dia do evento, a qual poderia levar até cinco mudas, e também para despertar um maior interesse pelas plantas. 
Figura 2 - Exemplo de ficha dendrológica previamente divulgada, contendo informações sobre as espécies disponíveis para doação no evento de extensão “Arboriza Ponta Grossa” realizado no dia 5 de junho de 2020, no município de Ponta GrossaPR.

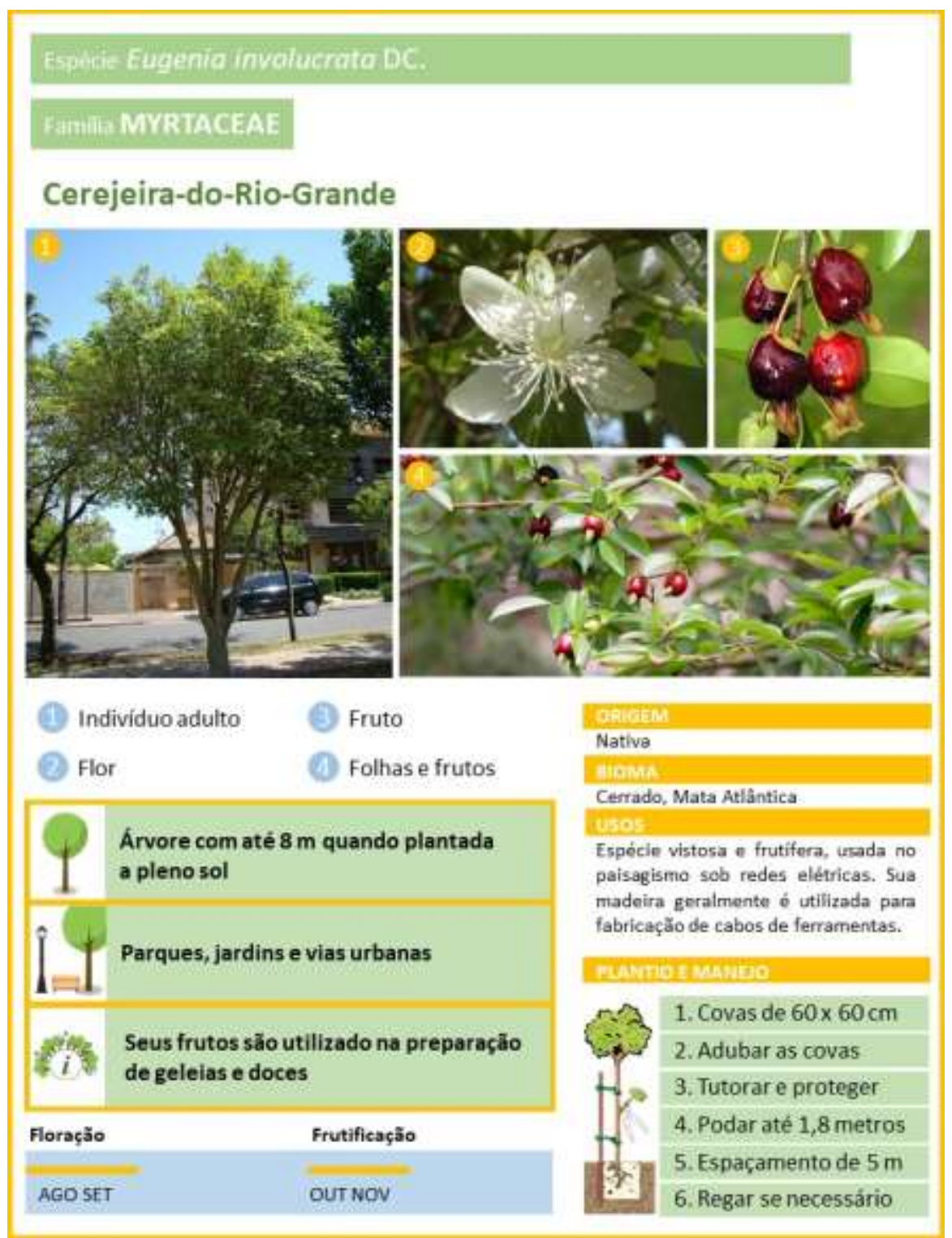

Fonte: Autores.

Dessa forma, a pesquisa realizada teve o intuito de obter informações sobre a população atendida e sobre a contribuição do evento para o entendimento da importância das árvores pelos participantes. Dentre as informações que buscouse levantar estão: destino das mudas recebidas, frequência com que as pessoas realizam o plantio de mudas arbóreas e importância das árvores enquanto propiciadoras de benefícios à população. Para isso, a pesquisa fundamentou-se em uma abordagem de cunho qualitativo e como ferramenta de coleta de dados utilizou-se um questionário composto por sete perguntas, sendo cinco questões objetivas e duas subjetivas. O questionário foi aplicado às pessoas que participaram do evento “Arboriza Ponta Grossa”, sem distinção, participando da pesquisa tanto a comunidade acadêmica da UEPG como a comunidade externa. As respostas das perguntas objetivas foram analisadas a partir das frequências das respostas observadas (representadas em porcentagem) utilizando-se ferramentas do programa Excel para a construção de gráficos. Com relação à pergunta subjetiva sobre o principal papel das árvores enquanto propiciadoras de benefícios à população, por meio do 
aplicativo Word Cloud Art Creator foi elaborada uma nuvem de palavras a partir das respostas, que estabelece uma organização gráfica dos termos, de acordo com suas frequências. Na figura as palavras são posicionadas aleatoriamente de tal forma que as respostas mais frequentes aparecem maiores que as outras, demonstrando assim seu destaque no corpus de análise da questão, permitindo uma melhor identificação do significado das respostas (Prais \& Rosa, 2017).

O projeto foi aprovado pelo Comitê de Ética em Pesquisa envolvendo Seres Humanos da Universidade Estadual de Ponta Grossa - CEP/UEPG, na Plataforma Brasil (http://plataformabrasil.saude.gov.br/login.jsf), com Certificado de Apresentação de Apreciação Ética (CAAE) n 26161119.5.0000.0105, sob o parecer 3.772.873.

\section{Resultados}

Estima-se que ao todo passaram pelo evento aproximadamente 500 famílias e foram doadas cerca de 3000 mudas, com bom alcance da população das principais localidades do município de Ponta Grossa, além de municípios próximos. Contudo, participaram da pesquisa um total de 138 pessoas. Destas, 87,3\% residem na cidade de Ponta Grossa, atingindo um total de 48 localidades do município. Dentre as outras cidades atendidas, destacam-se Palmeira (2,0\%), Ipiranga (2,0\%), Tibagi (1,3\%), Carambeí (1,3\%) e Ivaí (1,3\%) (Figura 3).

Figura 3 - Distribuição dos percentuais de participantes beneficiados pelo evento de extensão "Arboriza Ponta Grossa" realizado no dia 5 de junho de 2020 no município de Ponta Grossa-PR, por localidade no município de Ponta Grossa e demais cidades. As dimensões dos círculos representam os percentuais de 0,8 a 28,9\% para as localidades em Ponta Grossa (verde) e de 0,7 a $2,0 \%$ para as demais cidades (azul).

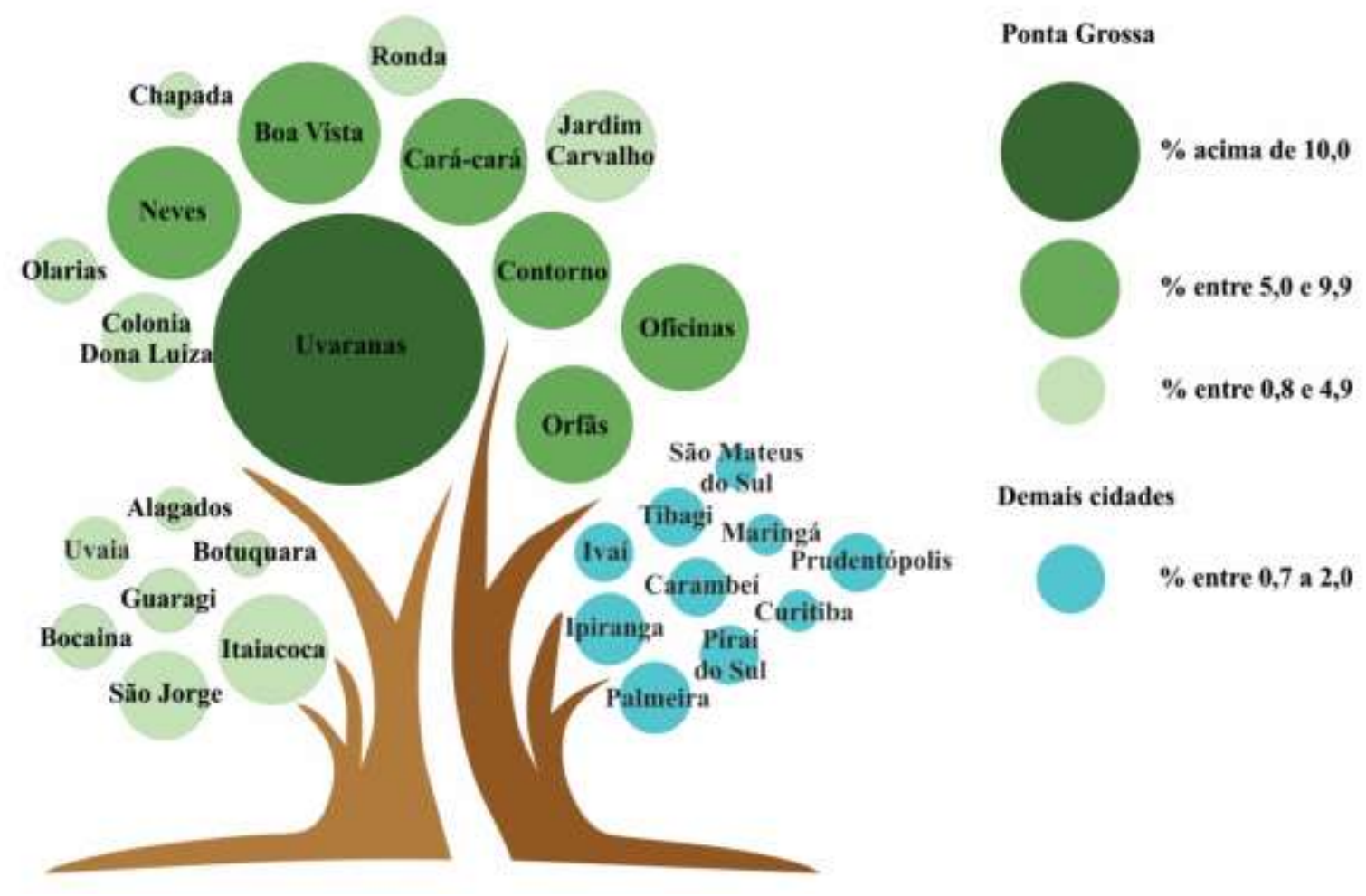

Fonte: Autores.

Com relação à caracterização do público participante do evento nesta edição, este foi majoritariamente composto pela comunidade externa à UEPG (Figura 4). 
Figura 4 - Caracterização do público participante do evento de extensão "Arboriza Ponta Grossa" realizado no dia 5 de junho de 2020 no município de Ponta Grossa-PR.

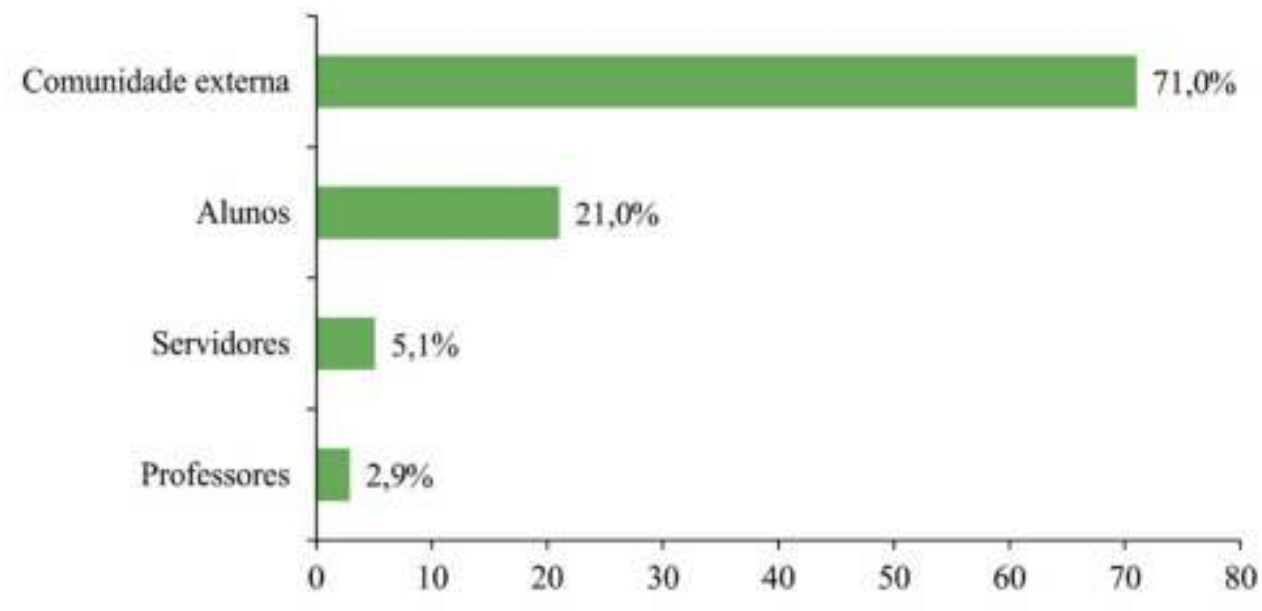

Fonte: Autores.

Além da maior adesão da comunidade externa ao evento, chamou a atenção o fato de grande parte dos entrevistados, $73,2 \%$, estarem participando pela primeira vez de um evento de doação de mudas como o "Arboriza Ponta Grossa". Apesar disso, a maioria dos participantes disse já possuir experiência com o plantio de arbóreas, realizando frequentemente o plantio de mudas ou pelo menos algumas vezes (Figura 5).

Figura 5 - Frequência relatada pelos entrevistados do evento de extensão "Arboriza Ponta Grossa" realizado no dia 5 de junho de 2020 no município de Ponta Grossa-PR, para a pergunta: Com que frequência você realiza o plantio de árvores?

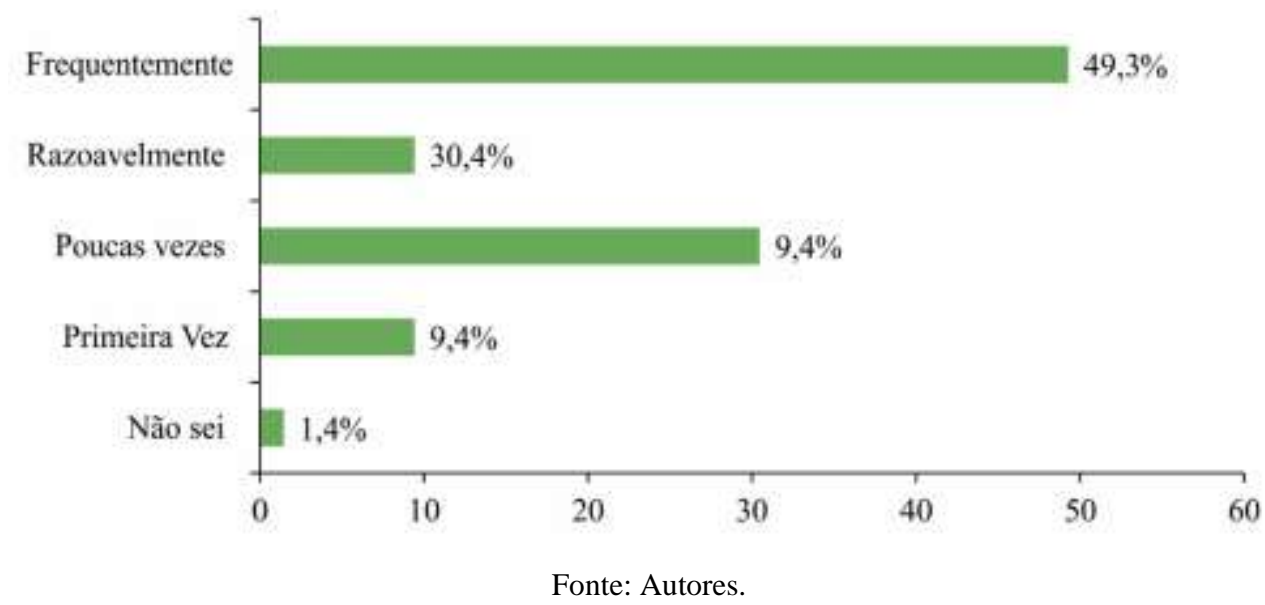

Quando os participantes foram questionados sobre o local em que pretendiam realizar o plantio das mudas doadas, estas tiveram como principais destinos os quintais de suas residências (52,8\%) e áreas rurais (33,5\%) (Figura 6). 
Figura 6 - Principais destinos para as mudas doadas pelo evento de extensão "Arboriza Ponta Grossa" realizado no dia 5 de junho de 2020 no município de Ponta Grossa-PR.

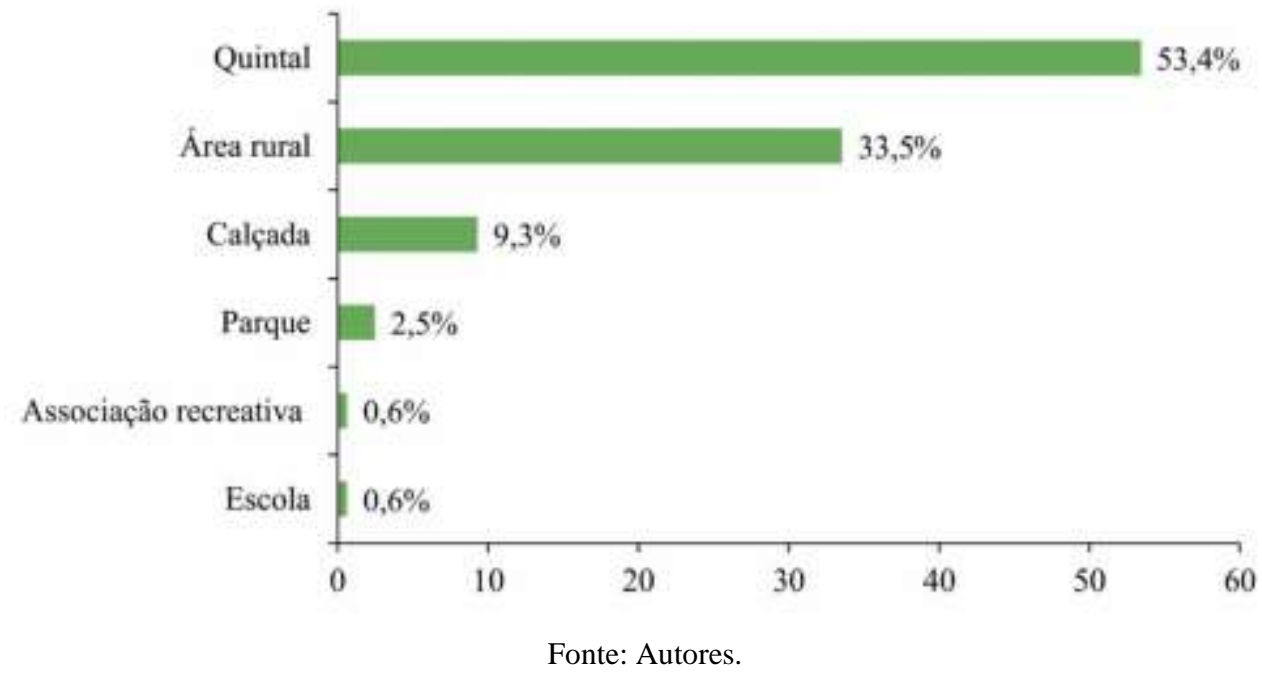

Ao responderem sobre a contribuição do evento para o aumento do interesse e curiosidade pelas plantas e pelo seu papel na arborização urbana (Figura 7), a grande maioria dos entrevistados respondeu positivamente e apenas um pequeno percentual considerou que o evento não foi eficiente em despertar maior interesse e/ou curiosidade a respeito da arborização.

Figura 7 - Contribuição do evento de extensão “Arboriza Ponta Grossa” realizado no dia 5 de junho de 2020 no município de Ponta Grossa-PR, para o despertar do interesse e curiosidade dos participantes a respeito da importância da arborização urbana.

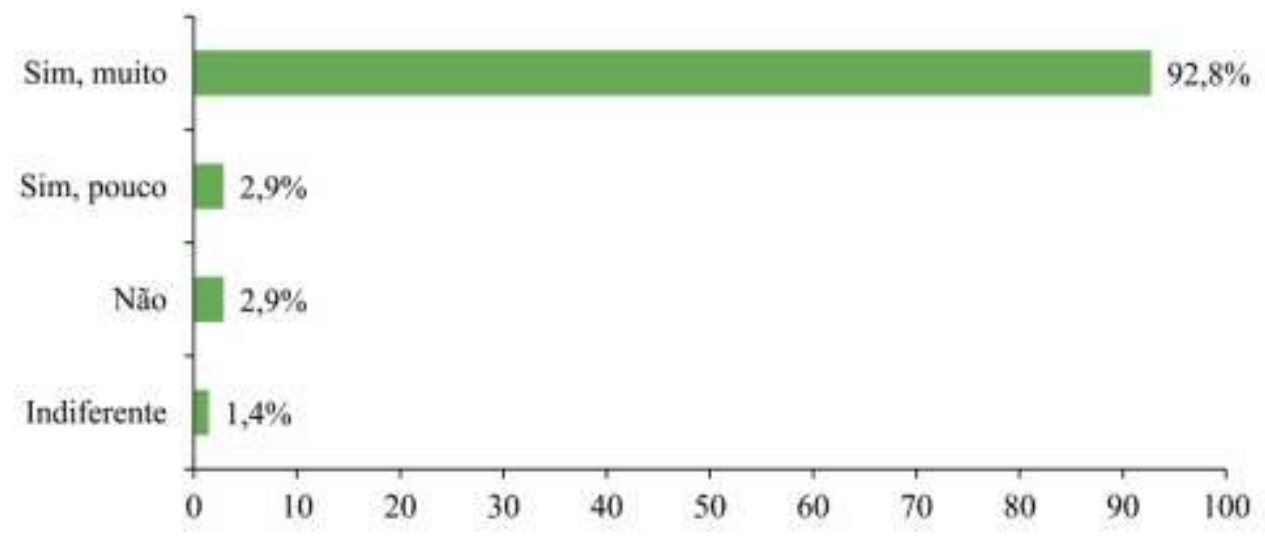

Fonte: Autores.

Além da contribuição do evento, quando os participantes foram questionados sobre o seu principal entendimento com relação ao papel das árvores enquanto propiciadoras de benefícios à população (Figura 8), o principal benefício apontado foi a importância das árvores para a qualidade do ar (28,5\%). Outros benefícios bastante destacados pelos entrevistados foram a produção de frutos $(19,8 \%)$, beleza estética $(18,4 \%)$ e fornecimento de sombra $(15,5 \%)$. 
Figura 8 - Nuvem de palavras elaborada a partir das respostas dos entrevistados do evento de extensão "Arboriza Ponta Grossa" realizado no dia 5 de junho de 2020 no município de Ponta Grossa-PR à questão: $O$ que em primeiro lugar as árvores representam para você?

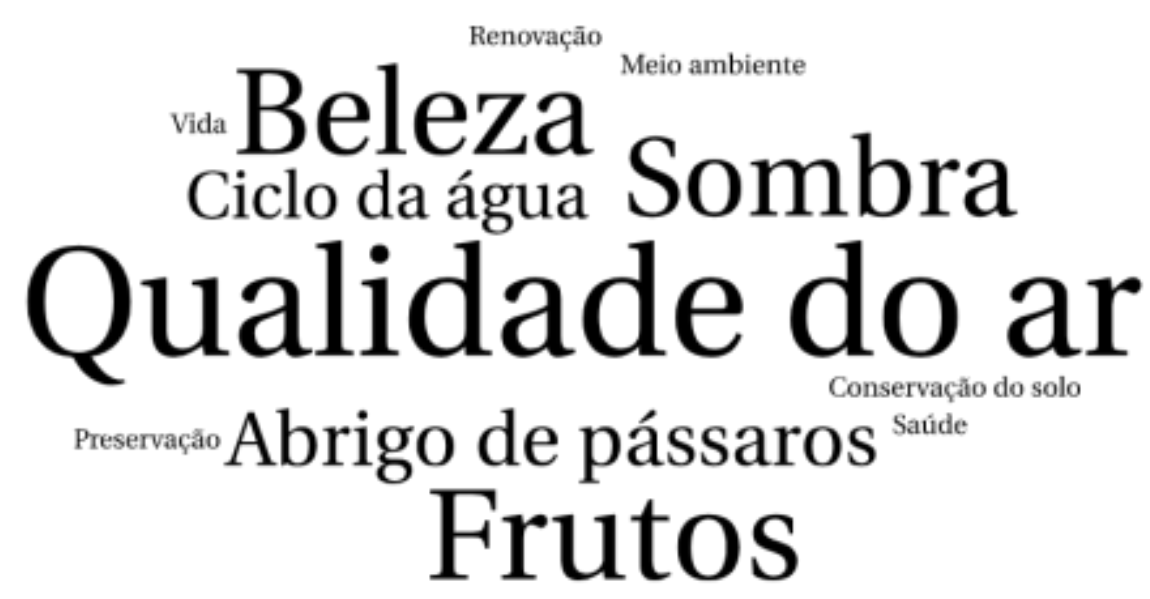

Fonte: Autores.

\section{Discussão}

Verificou-se que, apesar da pandemia do Covid-19, o alcance do público ao evento foi superior ao vislumbrado pelos organizadores, sendo superior, inclusive, ao verificado na edição anterior do evento, com elevado interesse da população por plantas para uso em ambientes urbanos e rurais. A localidade com maior percentual de distribuição das mudas foi o bairro Uvaranas (28,9\%) (Figura 3), o que se justifica por ser o bairro mais populoso do município e também o mais próximo ao local do evento. Destaca-se que os participantes do evento pertenceram majoritariamente à comunidade externa da UEPG (Figura 4), o que sinaliza uma maior adesão da população em geral e chama a atenção para o interesse desta na participação de eventos de Educação Ambiental. Por outro lado, a menor participação da comunidade acadêmica pode ter ocorrido em função das aulas presenciais estarem suspensas na data de realização do "Arboriza Ponta Grossa", devido à pandemia do Covid-19, e por muitos servidores estarem em trabalho remoto, diferindo do verificado no evento realizado no ano anterior, no qual houve maior participação da comunidade acadêmica. Ainda, como muitos alunos não residem em Ponta Grossa, há uma maior dificuldade no seu deslocamento, o que pode ter interferido na sua participação.

Pressupõe-se que o fato de muitas famílias terem participado do evento pela primeira vez (73,2\% dos entrevistados) ocorreu devido ao aumento de pessoas em casa realizando trabalho remoto. Isso pode ter levado à uma maior percepção da necessidade de melhorar o ambiente residencial, sendo o cultivo de plantas associado ao bem-estar emocional por muitos adeptos (Londe \& Mendes, 2014), o que corrobora com os resultados da pesquisa, que apontam uma maior procura de plantas para quintais $(53,4 \%)$ (Figura 6). Deve-se ressaltar que a definição de quintais é ampla, pois constituem espaços complexos dentro dos limites de uma dada natureza construída, onde se cultivam essências vegetais, como hortaliças e árvores. Nos aglomerados urbanos ou nas áreas rurais, os quintais são extensões das casas que abastecem a família e a vizinhança e propiciam a interação do homem com o ambiente natural por meio do plantio, manejo, colheita e consumo dos vegetais (Meneses, 2015). Além disso, as áreas rurais, que estiveram em segundo lugar (33,5\%), contribuíram não apenas com o percentual de arborização dos municípios envolvidos, ainda que em pequena escala, mas também com a melhoria das características ecológicas de propriedades rurais, seja pelas mudas doadas ou pelo estímulo à preservação ambiental. O transcender do evento para além das fronteiras urbanas é bastante interessante, uma vez que as atividades produtivas do campo 
implicam, muitas vezes, em elevado potencial de danos ao meio ambiente, por trabalharem diretamente com os recursos naturais.

O Instituto Brasileiro de Geografia e Estatística (IBGE) estima que Ponta Grossa possui apenas 57,2\% de domicílios urbanos em vias públicas com arborização (IBGE, 2010), índice baixo se comparado com outros municípios do Estado do Paraná, como Maringá com 97,5\% e Londrina com 96,5\%, o que lhe confere a $335^{\mathrm{a}}$ posição (de $399^{\mathrm{a}}$ ) no ranking de arborização em vias públicas. Essa realidade está atrelada, muitas vezes, a um desenvolvimento do município pouco preocupado às questões ambientais e desconhecimento sobre o assunto, como é frequente em muitos municípios brasileiros e também no município de Ponta Grossa, devido ao processo acelerado e contínuo de urbanização (Carneiro \& Carvalho, 2013). Considerando que 97,8\% da população do município reside em zona urbana (IBGE, 2010), ressalta-se a importância de ações de Educação Ambiental que visem conscientizar a população a respeito da importância da implantação de árvores na cidade e que atinjam um público abrangente e diversificado. Tais ações são necessárias não apenas por aludir à importância das árvores, mas também por melhorar o envolvimento da população no planejamento e gerenciamento da arborização urbana nas esferas pública e privada.

Nesse sentido, eventos de doação de mudas aliados ao repasse de conhecimentos técnicos por profissionais capacitados tendem a ser mais efetivos e benéficos do que eventos que possuam como objetivo a simples distribuição de mudas à população. Isso tem sido apontado por outros estudos semelhantes, que destacam que a Educação Ambiental aliada ao conhecimento constitui uma ferramenta fundamental nas mudanças de conceitos e atitudes com relação à conservação dos recursos naturais (Martelli, 2015; Cerqueira et al., 2020). Da mesma forma, o fornecimento de folders com informações sobre o plantio e fichas dendrológicas das espécies, como foi realizado pelo "Arboriza Ponta Grossa", além das instruções dadas pelos organizadores, pode auxiliar participantes de eventos a escolherem de modo mais adequado plantas condizentes com os espaços que pretendem realizar o plantio, colaborando com o planejamento da arborização urbana, o qual tem grande importância na gestão das cidades e no alcance da sustentabilidade urbana (Locastro et al., 2017).

Isso é importante, pois embora a maior parte dos participantes tenha respondido que realizam frequentemente o plantio de árvores (49,3\%) (Figura 5), isso pode ocorrer muitas vezes de modo inadequado, resultando em problemas urbanos como obstrução da iluminação e placas de sinalização, danos na fiação elétrica e na pavimentação, bem como na queda de frutos e galhos sobre veículos e pedestres (Landgraf et al., 2013; Luz, 2012; Gonçalves et al., 2018; Cunha et al., 2020). Além disso, a confecção de materiais de divulgação científica permite tornar determinados temas mais atrativos à comunidade em geral, de modo a contribuir para o seu desenvolvimento científico e social (Silva \& Oliveira, 2020), auxiliando tanto pessoas que já realizam o plantio de árvores por conta própria e, sobretudo, pessoas que o estão realizando pela primeira vez. Segundo os relatos dos organizadores do evento "Plante Essa Ideia", promovido anualmente pelo Programa de Educação Tutorial de Engenharia Florestal (PET-EF) da UTFPR, Campus Dois Vizinhos, Paraná, materiais de divulgação científica que buscam associar imagens, textos e esquemas facilitam a compreensão de informações pela população, permitindo uma maior socialização desta para fora dos limites das instituições de ensino e pesquisa (Cerqueira et al., 2020). Tais esforços proporcionam a aproximação da sociedade, a qual muitas vezes encontra-se mergulhada em problemas que carecem de soluções imediatas, que não lhes permitem compreender ou respeitar a importância do ambiente natural. Isso é perceptível, por exemplo, quando integrantes da comunidade vêm em busca de mais informações, seja por meio das redes sociais do Viveiro Florestal UEPG/CAAR, ou até mesmo de modo presencial.

Além disso, a aproximação da comunidade torna-se especialmente importante quando se verifica que a contribuição de eventos como o "Arboriza Ponta Grossa" para o aumento do interesse e curiosidade pelas plantas e pelo seu papel na arborização urbana é de fato relevante $(92,8 \%)$, conforme apontado pelos participantes (Figura 7). Particularmente nos centros urbanos, onde há maior distanciamento entre as pessoas e os ambientes naturais e, por consequência, onde a "cegueira 
botânica" está mais presente, a abertura de diálogos com a sociedade, além de complementar as ações do educador ambiental, permite um maior entendimento por parte desta acerca da importância das plantas para a manutenção dos ambientes ecológicos. Mesmo nos ambientes urbanos, a presença de árvores de espécies nativas, além de fornecer abrigo e alimentos para a fauna (Oliveira et al., 2013), podem atuar como estoques diversificados de materiais genéticos, facilitando a obtenção de matrizes que podem ser utilizadas no fornecimento de sementes para a produção de mudas visando a restauração de ecossistemas degradados presentes na região (Kabashima et al., 2011).

As árvores e as vegetações associadas têm inúmeros usos e funções no ambiente urbano, e os benefícios destacados pelos participantes do evento enquadram-se como serviços ecossistêmicos de provisões, de regulação e culturais, segundo a Plataforma Intergovernamental da Biodiversidade e Serviços Ecossistêmicos (IPBES, 2021) e a Classificação Internacional Comum dos Serviços Ecossistêmicos (CICES, 2021). O benefício mais citado, "melhoria da qualidade do ar" (serviço ecossistêmico de regulação), embora também seja o mais abstrato dos demais, destaca-se, possivelmente, devido à grande divulgação deste pela mídia em geral e pela frequente realização de campanhas que tratam do papel das árvores sobre a dispersão de poluentes resultantes de diversas atividades realizadas no meio urbano, como o intenso uso de veículos e queimadas, o que reforça que a Educação Ambiental ajuda a trazer conhecimentos significativos para a população. Associado frequentemente a melhoria do ar está também a "produção de sombra", devido ao maior conforto térmico proporcionado pela arborização urbana, em contraste aos centros urbanos intensamente concretados. As alterações nesse quesito referem-se à maior umidade relativa do ar, devido à evapotranspiração realizada pelas plantas, e redução das temperaturas (Pinheiro \& Souza, 2017). É interessante também destacar que inúmeros estudos apontam que altas concentrações de poluentes na atmosfera são considerados alarmantes e estão associados a quadros de doenças respiratórias e problemas cardíacos, além da diminuição da qualidade de vida da população (Dapper et al., 2016).

A "produção de frutos" (serviço ecossistêmico de provisão), outro benefício destacado pelos participantes do evento, costuma ser uma característica relevante na escolha de espécies para o plantio em quintais, sendo notável a grande procura da comunidade pelas arbóreas frutíferas Cerejeira-do-Rio-Grande (Eugenia involucrata), Jabuticaba (Plinia peruviana), Araçá (Psidium cattleyanum) e Pitanga (Eugenia uniflora), segundo os organizadores do evento. Como já comentado, a implantação de frutíferas no reflorestamento urbano, além de fornecer frutos para as pessoas, é necessária para que espécies da fauna silvestre tenham fontes de alimentos e possam se estabelecer (Silveira et al., 2019), desempenhando, adicionalmente, o controle de pragas e vetores (Lourenço \& Biagolini, 2018).

Já o benefício "embelezamento do ambiente" (serviço ecossistêmico cultural), destaca-se por ter sido o principal fator que historicamente contribuiu para a implantação da arborização nos municípios, possuindo grande apelo espiritual, cultural e de lazer. Espécies como os ipês (Handroanthus spp.) e manduirana (Senna macranthera), que apresentam floração vistosa, são com frequência preferidas pelas pessoas, constituindo espécies bem consolidadas na arborização de ruas, parques e jardins (Oliveira \& Rosin, 2013; Martelli \& Santos Júnior, 2015). Ademais, os outros benefícios apontados pelos participantes, como "ciclo da água", "conservação do solo" e "saúde", sinalizam a sua sensibilização acerca do papel da vegetação urbana e sobre a importância de resgatar tais valores nas sociedades atuais.

Diante do exposto, verifica-se que diversos estudos apontam para a importância das árvores em ambientes urbanos, que por meio de seus serviços ecossistêmicos fornecem qualidade de vida às pessoas. No entanto, mais do que doar mudas, ações como o evento "Arboriza Ponta Grossa” podem contribuir para suprir outra importante demanda nos municípios, que se refere à demanda por conhecimento em planejamento, implantação e manejo da arborização urbana, uma lacuna na sociedade, que se resolvida, pode trazer novas perspectivas para a arborização de Ponta Grossa. Durante o evento, tanto essa demanda foi perceptível, como a boa receptividade dos materiais (folder e ficha) elaborados com informações sobre as espécies e instruções de manejo, corroborando com os relatos dos organizadores do evento "Plante Essa Ideia" (Cerqueira et al., 2020). 
Da mesma forma, considera-se que tanto para a produção, manejo e expedição das mudas, como para o planejamento e execução do evento, foi necessário aos alunos envolvidos a aplicação de conhecimentos diversos adquiridos ao longo da graduação e também da experiência obtida junto aos projetos de pesquisa desenvolvidos pelo Viveiro Florestal UEPG/CAAR, o que ressalta a importância da universidade em desenvolver atividades de extensão durante o processo educacional. A interação da comunidade com os alunos representa uma oportunidade valiosa para a formação acadêmicas destes, elevando o nível de sensibilidade acerca da importância da arborização urbana para a comunidade, cumprindo assim, o compromisso com a sociedade na construção de valores sociais, conforme está presente na Constituição Federal de 1988, em seu artigo 207, que estabelece a indissociabilidade entre ensino, pesquisa e extensão, como dever para as universidades públicas (BRASIL, 1988).

\section{Considerações Finais}

Verifica-se que eventos de extensão como o "Arboriza Ponta Grossa" podem ser considerados eficientes na promoção da interação entre a universidade e a comunidade, interessada em receber informações sobre o plantio e manejo de espécies arbóreas. A hipótese da presente pesquisa foi corroborada, uma vez que o bom alcance do público e a adesão da população ao evento, verificados nesta pesquisa, demonstram o elevado interesse dos participantes em elevar os percentuais de plantas nos ambientes urbanos e rurais, e permite reforçar a importância de ações como essa para sensibilizar a comunidade em geral sobre o valor ecológico, social e econômico das florestas urbanas. Além disso, foi possível visualizar o perfil dos participantes e seus interesses e demandas relacionadas à arborização urbana, o que contribuirá para a realização de futuros eventos e pesquisas.

Considera-se que o "Arboriza Ponta Grossa", além da grande relevância enquanto instrumento para a Educação Ambiental, pode ser utilizado para objetivos de caráter educacionais e didáticos, tornando-se um importante subsídio para a formação acadêmica de futuros profissionais comprometidos com a sociedade. Isto porque possui um conjunto de ações que vão desde a produção e manejo das mudas em viveiro, até o planejamento e execução do evento, possibilitando a aplicação de conhecimentos diversos e trazendo novas perspectivas para a arborização no município de Ponta Grossa.

Por fim, em muitos municípios brasileiros, como em Ponta Grossa, a falta de planejamento urbano na expansão das cidades configura entre os principais entraves à arborização urbana. Nesse sentido, parcerias entre as universidades e os órgãos públicos como as secretarias municipais e estaduais de meio ambiente, poderiam contribuir para a implementação de programas de capacitação voltados ao planejamento, implantação e manejo das áreas verdes, além de ações de Educação Ambiental voltadas à preservação ambiental e melhoria da qualidade de vida da população.

\section{Agradecimentos}

Agradecemos a todos os participantes do evento de extensão "Arboriza Ponta Grossa" que voluntariamente responderam aos questionários e participaram da pesquisa, à organização do evento pela colaboração, disponibilidade e fornecimento de informações importantes ao desenvolvimento do projeto e à Universidade Estadual de Ponta Grossa por possibilitar e prover os meios para a execução da pesquisa.

\section{Referências}

Alencar, L. D., \& Barbosa, M. F. M. (2018). Educação Ambiental no Ensino Superior: ditames da Política Nacional de Educação Ambiental. Revista Direito Ambiental e Sociedade, Caxias do Sul, 8(2), 229-255. 10.18226/22370021.v8.n2.10

BRASIL. (1988). Constituição da República Federativa do Brasil. Brasília: Centro Gráfico.

Carneiro, D. C., \& Carvalho, S. M. (2013). As estruturas de gestão e planejamento da arborização urbana de Ponta Grossa - PR. Cidades Verdes, 1(1), 94-116. doi: $10.17271 / 23178604112013412$ 
Cerqueira, F. G., Santos, A. C. D. S., Thompson, B. B., Michalichen, G., Brito, G. G. S., Pereira, M. O. F, Kreczkiuski, C., Canonico, C. M., Porrua, D. A., Biolchi, G., Dias, H. M., Arancibia, I. A. L., Ribeiro, J. C. B., Minozzo, M., Reis, M. E. M., Felipe, N. A., Krefta, S. C., Potrich, M., \& Tessaro, D. (2020). Educação Ambiental -Percepções e reflexões pautadas no projeto "Plante Essa Ideia". Research, Society and Development, 9(9), e746997710. doi:10.33448/rsd-v9i9.7710

CICES - Classificação Internacional Comum dos Serviços Ecossistêmicos. (2021). https://cices.eu

Cunha, V. L. C. M., Magalhães, L. M. S., Freitas, W. K., \& de Mendonça, B. A. F. (2020). Conflitos da arborização com elementos urbanos na cidade de Valença, estado do Rio de Janeiro. Revista da Sociedade Brasileira de Arborização Urbana, 15(2), 28-41, 2020. doi:10.5380/revsbau.v15i2.69850

Dapper, S. N., Spohr, C., \& Zanini, R. R. (2016). Poluição do ar como fator de risco para a saúde: uma revisão sistemática no estado de São Paulo. Estudos Avançados, 30, 83-97. doi:10.1590/S0103-40142016.00100006

Duarte, T. E., Angeoletto, F. H. S., Santos, J. W. M. C., Leandro, D. S., Bohrer, J. F. C., Vacchiano, M. C., \& Leite, L. B. (2017). O Papel da Cobertura vegetal nos ambientes urbanos e sua influência na qualidade de vida nas cidades. Desenvolvimento em Questão, 15(40), 175-203. doi:10.21527/22376453.2017.40.175-203

Ferreira, L. C., Martins, L. D. C. F., Merotto, S. C., Raggi, D. G., \& da Silva, J. G. F. (2019). Educação ambiental e sustentabilidade na prática escolar. Revista Brasileira de Educação Ambiental (RevBEA), 14(2), 2019. doi:10.34024/revbea.2019.v14.2678

Gonçalves, L. M., Monteiro, P. H. S., Santos, L. S., Maia, N. J. C., \& Rosal, L. F. (2018). Arborização urbana: a importância do seu planejamento para qualidade de vida nas cidades. Ensaios e Ciência, 22(2), 128-136. doi:10.17921/1415-6938.2018v22n2p128-136

IBGE - Instituto Brasileiro de Geografia e Estatística. (2010). Arborização de vias públicas: IBGE, Censo Demográfico 2010. Retrieved July 30, 2021, from https://cidades.ibge.gov.br/brasil/pr/ponta-grossa/panorama

IPBES - Plataforma Intergovernamental da Biodiversidade e Serviços Ecossistêmicos. (2021). Retrieved July 30, 2021, from https://www.ipbes.net

Kabashima, Y., Andrade, M. L. F., Gandara, F. B., Tomas, F. L., Polizel, J. L., Velasco, G. D., Silva, L., Dozzo, A. D. P., Oliveira, R. G. M. G., \& Silva Filho, D. (2011). Histórico da composição da vegetação arbórea do Parque do Ibirapuera e sua contribuição para a conservação da biodiversidade. Revista da Sociedade Brasileira de Arborização Urbana, 6(4), 125-144. doi:10.5380/revsbau.v6i4.66492

Landgraf, P. R. C., Paiva, P. D. O., \& Reis, L. A. (2013). Desenvolvimento de software para o planejamento da arborização urbana. Revista Brasileira de Horticultura Ornamental, 19(1), 19-24. doi:10.14295/rbho.v19i1.571

Lima, Y. E. S. P., Lima, M. L. S. P., \& Gomes, E. G. (2018). A educação ambiental por meio do incentivo da arborização visando ao conforto térmico no Município de Bayeux, Estado da Paraíba, Brasil. Revista Brasileira de Gestão Ambiental e Sustentabilidade, 5(10), 799-804. 10.21438/rbgas.051028

Locastro, J. K., Miotto, J. L., Angelis, B. L. D., \& Caxambu, M. G. (2017). Avaliação do uso sustentável da arborização urbana no município de Cafeara, Paraná. Ciência Florestal, 27(2), 549-556. doi:10.5902/1980509827735

Londe, P. R., \& Mendes, P. C. (2014). A influência das áreas verdes na qualidade de vida urbana. Hygeia - Revista Brasileira de Geografia Médica e da Saúde, 10(18), 264-272. http://www.seer.ufu.br/index.php/hygeia/article/view/26487

Lourenço, R. W., \& Biagolini, C. H. (2018). Relação entre avifauna e plantas frutíferas em 10 parques lineares da cidade de São Paulo, (BRASIL). Conhecimento Interativo, 12(2), 70-81. doi:10.22533/at.ed.3471916042

Luz, S. A. (2012). Arborização urbana: importância e parâmetros para uma implantação adequada. Revista Thêma et Scientia, - Edição especial de arquitetura e Design, 2(2), 43-50. Retrieved from http://www.themaetscientia.fag.edu.br/index.php/RTES/article/view/107

Martelli, A. (2015). Educação Ambiental como método de favorecimento da arborização urbana do município de Itapira-SP. Revista Eletrônica em Gestão, Educação e Tecnologia Ambiental, 19(2), 1195-1203. 105902/2236117015895

Martelli, A., \& Santos Júnior, A. R. (2015). Arborização Urbana do município de Itapira-SP: perspectivas para educação ambiental e sua influência no conforto térmico. REGET/UFSM, 19(2), 1018-1031. doi:10.5902/2236117015968

Meneses, J. N. C. (2015). Pátio cercado por árvores de espinho e outras frutas, sem ordem e sem simetria: O quintal em vilas e arraiais de Minas Gerais (séculos XVIII e XIX). Anais do Museu Paulista: História e Cultura Material, 23(2), 69-92. doi:10.1590/1982-02672015v23n0203

Milach, E.M., Louzada, M. C., \& Abrão, R. K. (2016). O espaço verde nas escolas de educação infantil. Revista CIPPUS, 6(1), 1-11.

Oliveira, M. V. M., \& Rosin, J. A. R. G. (2013). Arborização dos espaços públicos: uma contribuição à sustentabilidade urbana. Revista Nacional de Gerenciamento de Cidades, 1(3), 1-14. doi:10.17271/23188472132013451

OMS - Organização Mundial da Saúde (1995). Veinte pasos para formular un proyecto de ciudades sanas. Washington: Organización Panamericana de la Salud. División de Promoción y Protección de la Salud.

Pinheiro, C. R., \& Souza, D. D. (2017). A importância da arborização nas cidades e sua influência no microclima. Revista Gestão \& Sustentabilidade Ambiental, 6(1), 67-82. doi:10.19177/rgsa.v6e1201767-82

Prais, J. L. S., \& Rosa, V. F. (2017). Nuvem de palavras e mapa conceitual: estratégias e recursos tecnológicos na prática pedagógica. Nuances: estudos sobre Educação, 28(1), 201-219. doi:10.14572/nuances.v28i1.4833

Silva, J. O. R., \& Oliveira, M. S. (2020). Arborização urbana e a educação ambiental como fator conscientizador. Scientia Generalis, 1(2), 1-10. Retrieved from http://scientiageneralis.com.br/index.php/SG/article/view/24 
Research, Society and Development, v. 10, n. 10, e79101018332, 2021

(CC BY 4.0) | ISSN 2525-3409 | DOI: http://dx.doi.org/10.33448/rsd-v10i10.18332

Silveira, G. V. S, Batista, Z. A., Silva, C. J., Silva, N. N., \& Silva, H. R. (2019). Inventário faunístico de um fragmento florestal urbano no Semiárido Brasileiro. Agropecuária Científica no Semiárido, 15(3), 148-152. doi:10.30969/acsa.v15i3.1163

Ugeda Júnior, J. C. (2014). Planejamento da paisagem e planejamento urbano: reflexões sobre a urbanização brasileira. Revista Mato-Grossense de Geografia, 17(1), 101-116. https://periodicoscientificos.ufmt.br/ojs/index.php/geografia/article/view/764

Vasques, D. T., Freitas, K. C. \& Ursi, S. (2021). Aprendizado ativo no ensino de botânica. São Paulo: Instituto de Biociências, Universidade de São Paulo.

Wandersee, J. H., \& Schussler, E. E. (2001). Towards a theory of plant blindness. Plant Science Bulletin, 47(1), 2-9. https://www.botany.org/userdata/IssueArchive/issues/originalfile/PSB_2001_47_1.pdf 